\title{
Study of Cultural Infiltration Methods on Primary Stage of Chinese for Foreigners Teaching
}

\author{
Qian Liang ${ }^{1, a}$ \\ ${ }^{1}$ International Exchange Center, Xi'an International University, Xi'an, Shaanxi, 710077 \\ ${ }^{\mathrm{a}}$ email
}

Keywords: Chinese for Foreigners, Cultural Teaching, Cultural Infiltration, Method

\begin{abstract}
As China is accelerating the process of integration into the international and Chinese for its unique beauty and extraordinary expressive glow with new life in the light of the world civilization in the river. The rise of Chinese hot to China's TCFL challenges. Culture teaching foreign language teaching is a very important part, the majority of language educators emphasis on teaching Chinese Foreign Culture Teaching increasingly high. But the vast majority of the low level of Chinese students, not suitable for opening specialized culture courses. In order to better equip students with profound Chinese culture, this paper shallow teaching experience, to make a few cultural reference penetration strategies in teaching.
\end{abstract}

\section{Introduction}

From the point of view of law culture acquisition, for foreigners, to learn Chinese, only basic knowledge of the language is not enough, language is the carrier of culture and presenting content, in order to achieve intercultural communication and communication between, we must firmly grasp the cultural connotations of the language of the host. Based on the relationship between language and culture, the process of teaching Chinese as a Foreign Culture Teaching required [1]. But Chinese culture courses usually belong to intermediate and advanced students in the class of elective courses, and the Chinese Culture Foundation and elementary students in the class of poor students is difficult to digest by cultural curriculum to really grasp Chinese culture. The cultural penetration is a subtle way, the students on the basis of capacity requirements low for the primary stage of students' basic learning situation. This article from the reality, discusses the basic principles of the primary stage of cultural penetration, and describes the specific implementation method of teaching cases.

\section{Cultural Penetration Characteristics and Status on Primary Stage of Chinese for Foreigners Teaching}

The content and characteristics of the cultural penetration. Language is the way cultural transmission, is to reveal the window and record keeping culture carrier. At the same time, only the language is deeply rooted in the soil of culture, to make cultural heritage more rich, more established. Because each nation has its own cultural characteristics, resulting in the structure of language vary, restricted the cross-cultural communication and mutual understanding. Cultural penetration is open this door Pragmatic strangeness of the key, therefore, in the primary stage of Chinese teaching of foreign cultural infiltration of great significance [2]. Cultural infiltration ultimate purpose of teaching is to help students fully understand the various parts of Chinese culture, it mainly includes the following representative and typical content: Chinese people's traditional ideas and psychological characteristics; lifestyle and customs; China's fundamental political basic knowledge of cultural geography; passed down through generations of Chinese cultural treasures, such as the "four great inventions" and so on.

The current status of teaching of cultural penetration. Teaching Chinese as a combination of cultural factors have become the consensus of the permeation of foreign language teaching teachers, however, from the current status of implementation, the results achieved are not satisfactory. The reason there are several aspects: First, cognitive bias in consciousness. Many people believe that 
cultural penetration is dedicated to teach Chinese culture, and not combined with the use of language, from the context of actual communication; there is thought of by the traditional examination-oriented education shackles, still scores to measure, and had no time taking into account the multi-cultural teaching content and deliver a deeper level than the textbook; second, relatively low level of education. The quality of teaching and level of comprehensive quality and business skills teachers have a close relationship. Learning and education and training some late Foreign Language teachers not keep pace with the times, the results because of the limited level of teaching methods lead to a single, field of vision, although there is a strong Chinese modern literacy, but the lack of profound cultural foundation, so the impact lectures and enthusiasm of students learning enthusiasm.

\section{The Basic Principles of in Primary Stage of Chinese for Foreigners Teaching}

Select the appropriate cultural materials. Chinese cultural content is comprehensive, up to the spirit of the system, down to the basic necessities of life, but in the early stages as a Foreign Language, can not cover everything. And combined with the teaching objectives of Foreign Language, select the basic direction should be the communication process involved, for language teaching and services, and education and to students' pragmatic level of communication needs to match [3]. Therefore, to select a representative, mainstream, based on cultural factors start teaching.

Cultural penetration enough is enough. Chinese language classes for elementary students and teachers in the design of teaching programs should fully consider the cultural background and Chinese master degree students, teaching should therefore cultural penetration is relatively plain, easy to understand and accept the student, as long as they allow communication the break communication barriers, reduce misunderstanding and trouble, and stimulate their interest in learning more in-depth study to lay the foundation to your goal. Extend and expand too much can backfire, causing weary mood.

To interesting cultural infiltration. "Well it's not the music." If the teacher still theoretically in accordance with the teaching of basic courses as the traditional "chalk and talk", due to the gap of cultural differences, cultural re-rich material even if selected will obliterate it wonderful. Therefore, teachers must not only change their ideas, innovative teaching methods; and to be good at introducing visual cultural context and interesting stories, classroom teaching practices to assist [4]. Truly entertaining, fun and practical realization of unity.

The cultural penetration should be gradual. For the initial stage of the students, according to their order of logical thinking development organization of teaching activities. Beginning of new things, will inevitably produce psychological fear of difficulty and exclusion. Therefore, teachers should be careful look like progressive approach to the implementation of teaching, to a degree of relaxation, should not be too hasty. For example, when confronted with unfamiliar words, teachers should focus on a simple explanation from their shape, spelling, meaning, etc., on this basis, then transition to the deep meaning behind it.

\section{Cultural Infiltration Methods on Primary Stage of Chinese for Foreigners Teaching}

After analyzing the cultural penetration of Chinese teaching contents and principles, defined the basic features of the primary stage of learning Chinese, the following combination of teaching practice cases, proposed the implementation of the Primary Stage of Chinese language teaching methods.

Direct penetration means that the basic meaning of intuitive teaching method to tell the students some of the vocabulary. You can make use of pictures, information, stories and even poems including physical isochronous explain the cultural significance of the words contained. Thus for the primary stage of students, easier to understand and master.

Such as those involving the "Chinese Language Course" in some proper nouns About this Beijing, such as the "Great Wall", "Palace", "Summer Palace," "alley child", teachers can show their landscape characteristics through the corresponding image, the initial stage of students master the 
vocabulary of Chinese express much, but at least it can be beautiful, good initial feelings express opinion, on the basis of the concept of teachers to further clarify and summarize the characteristics of these sites allow students heartfelt praise; another example in the study " Mei "," blue "," bamboo "when" daisy "this word, we know that these four plants in Chinese culture is known as the" four gentlemen ", but implies ancient scholars and Confucian school heavy moral qualities and quality expectations. Therefore, when teaching, learning Chinese for the primary stage of students, teachers and the removal of Tang Dynasty in the popular easy to understand poetry, like Wang Anshi "plum"; or choose classic literati ink has spread, like Zheng Banqiao's "Bamboo" ; or the abundant charm of the story "Mei wife Tsuruko" and to realize the transition from the characteristics of the plant to the quality of human nature, and thus spiritual culture goods Wu vocabulary.

The creation of a real situation and the case of teaching cultural infiltration

Context is relying on language use environment, and allows students to create a vivid scene of the ground, to consolidate what they have learned in repeated practice, and further understanding of vocabulary, using words [5]. Therefore, teachers may be teaching cultural infiltration by organized performances and other classroom activities.

Such as interpersonal communication language is the basic language of communication, there are greeting, farewell, greetings, thank language and so on. Since the communication language is the product of countries and regions, thus corresponding to different areas of communication language used by the influence of local customs and habits of language, it carries different cultural factors. Chinese people meet each other in greeting when it will say "eaten me", "Recently it right away"; farewell will get up and say "sit a while" or told "pay attention to Tim clothes," etc. These and everyday life greeting or farewell, but many European countries are more concerned about the objective existence of things, such as the weather, which the bank what happened, government policy changes and the like. In the opinion of foreigners is difficult to understand why very minor topic privacy can be formed into the surface. In order to deepen their impression and differentiate, teachers can be summarized Sorry to interrupt, sorry terms such then let the students perform various occasions such as a visitor, meet role during the meal, so that students experience the different cultures in the context of appropriate expression, this is much more than simply explain the relatively intuitive.

The so-called life practice refers to guide learners in contact around the life of people and things, so that they integrate into the Chinese people's life, thereby expanding their horizons to feel the charm of culture; or the development of hands-on, such as imitation painting, paper-cut, so that they experience learned the meaning of the vocabulary of cultural factors.

For example, in learning about Chinese-style wedding customs introduction, due to the limited vocabulary of new textbooks given, there may be some illustrations, but the details are not portrayed in detail, the wedding process and more complex, in order to allow students to fully familiar with the customs, understand the process, teachers can led the students to use the holiday to attend a local wedding complete; in the study, "bronze", "fan" "and Tian" word, the teacher can lead students to the Folk Museum, Museum display location, personally feel the exquisite artifacts, and hear on the tour; learning "Peking opera", "Facebook" when teachers can allow students to try to draw on paper Guan Gong, Cao Cao and other classic facial appearance; in the study, "shadow", "paper-cut" and other words, you can let students against teachers take over a sample began cutting shears; learning "buns", "fruit pancake", "donut" "bean flowers" and other words, the teacher can take students to the streets, even the supermarket can reach breakfast shop operators on-site production of these foods, to enable students to watch and savor the feelings of Chinese culture at the same time, increase their cultural experience of learning Chinese culture and enthusiasm. These cultural factors in life will blend together casually, students can absorb multiple knowledge cultures.

\section{Conclusion}

All in all, the teaching of foreign students in the primary stage of Chinese contacts Chinese and Chinese culture period, a special cultural program for them, with a higher degree of difficulty. Cultural infiltration in line with the characteristics of students at the primary stage of Foreign 
Chinese teaching, teaching content can be avoided and a smattering of students, but also enrich their cultural experience, thereby increasing interest in learning Chinese language. Of course, the cultural penetration ways and means far more than those mentioned in the text, teachers also need to combine teaching practice, continue to study and explore the cultural infiltration of teaching strategies to help students improve their Chinese primary stage.

\section{References}

[1] Wang Miao. perception in the nursery rhyme in Chinese culture - Culture Teaching of Foreign Language Teaching in Primary Stage [J]. Guangdong Polytechnic Normal University, 2011,11: 133-135.

[2] Zhou Yuping. Teaching Chinese Cultural Infiltration - on "Chinese Bridge" Competition in China, students raised questions of culture [J]. Lanzhou Institute of Education, 2013,04: 83-85.

[3] Fu Xiaoli. Review Character Teaching Foreign Language Teaching [J]. Yunan Normal University (Teaching and Research on Foreign Language Edition), 2015,02: 31-46.

[4] Shi Huimin. division will sensitization study [J]. Primary Stage of Foreign Language Integrated Teaching Mode of Chongqing University of Science and Technology (Social Science Edition), 2012,04: 185-186.

[5] Feng Linyu. Several Issues of Teaching Chinese Character Teaching in Primary Stage [J]. Yangtze academic, 2010,01: 132-137. 